\title{
Transplantation of neural stem cells enhances expression of synaptic protein and promotes functional recovery in a rat model of traumatic brain injury
}

\author{
HAIYING MA ${ }^{1,3}$, BO YU $^{2}$, LI KONG $^{1,3}$, YUANYUAN ZHANG $^{3,4}$ and YUXIU SHI ${ }^{1}$ \\ ${ }^{1}$ Department of Histology and Embryology, Institute of Pathology and Pathophysiology, China Medical University, \\ Heping District, Shenyang 110001; ${ }^{2}$ Department of Neurosurgery, Shengjing Hospital Affiliated to China \\ Medical University, Shenyang 110004; ${ }^{3}$ Department of Histology and Embryology, Dalian Medical University, \\ Liaoning 116044, P.R. China; ${ }^{4}$ Wake Forest Institute for Regenerative Medicine, Winston-Salem, NC 27157, USA
}

Received May 27, 2011; Accepted June 10, 2011

DOI: $10.3892 / \mathrm{mmr} .2011 .510$

\begin{abstract}
Transplantion of neural stem cells (NSCs) has shown promise for the treatment of traumatic brain injury (TBI). Although the functional mechanisms underlying transplant-mediated recovery following TBI have yet to be determined, previous studies demonstrated that transplanted NSCs may respond to the release of specific neurotransmitters, and/or the production of factors that promote neuronal growth. Therefore, we hypothesize that the direct transplantation of NSCs into the injured brain enhanced the expression of synaptic protein and regeneration-associated protein, which may be responsible for promoting functional recovery in a rat model of TBI. Our results showed that NSC transplant significantly improved neurological motor function in selected behavioral tests compared to saline control rats. Our data showed that the number of surviving cells engrafted into the rats was $4.1 \pm 0.9 \%$ of engrafted cells at 8 weeks post-transplantation, with $11.4 \pm 1.6 \% \beta$ III-tubulin-immunopositive cells of these cells. RT-PCR and Western blot analysis demonstrated that the expression of synaptophysin (SYP) and regeneration-associated protein (GAP43) in the injured brain of NSC-transplanted rats was significantly increased compared to the saline control rats during the experimental period. These data suggest that NSCs transplanted directly into the injured brain are capable of surviving, differentiating into neurons and promoting functional recovery in a rat model of TBI. Engrafted NSCs increase the expression of SYP and GAP43 in the injured brain of NSC-transplanted rats, which is suggested as one of the mechanisms underlying the improved functional
\end{abstract}

Correspondence to: Professor Yuxiu Shi, Department of Histology and Embryology, China Medical University, 92 Beima Road, Heping, Shenyang 110001, P.R. China

E-mail: yuxiushi@163.com

Key words: neural stem cell, transplantation, traumatic brain injury, synaptogenesis recovery on motor behavior due to the transplantation of NSCs following TBI.

\section{Introduction}

Traumatic brain injury (TBI) is currently one of the major causes of disability, particularly in children and young adults in developed countries (1). These injuries have both short- and long-term effects on individuals, their families and society. Currently, effective strategies required for treating TBI patients and supporting the recovery of their lost functions are minimal. Long-term strategies incorporating the sustained release of trophic factors and encapsulated cell therapy have demonstrated feasibility (2), but may face clinical limitations such as volume constraints and the inability of donor cells to interact with the host tissue.

The characterization of neural stem/progenitor cells (NSCs) have led to new possibilities for direct transplantation of these cells into the injured brain, due to the multipotential ability to renew these cells and to generate neurons, astrocytes and oligodendrocytes. Moreover, their inherent ability to adapt to signals from the host cells and the extracellular environment is crucial for the donor cells to interact with the host tissue and regeneration of injured tissue (3). Previous experimental studies in animal models of human neurodegenerative disease showed that recovery of the lost neurological functions and partial reconstruction of neural circuitry was possible with the transplantation of NSCs in the damaged adult brain (4). Transplanted NSCs have been shown to differentiate into a number of phenotypes that promote repair and restoration of function according to the transplant location after injury or disease in the CNS, including TBI (5). However, the functional mechanisms underlying transplant-mediated recovery following TBI have yet to be determined.

The ability of engrafted NSCs to establish and maintain synaptic contacts is considered to be one of the basic requirements for intercellular communication and functional integration into existing neuronal networks. Synaptic and axonal regeneration after brain injury is crucial for the prediction of the neural compensation that may be achieved following 
various types of injury (6). Synaptophysin (SYP) plays a role in activity-dependent competitive synapse formation (7). Since loss of synapse correlates with the degree of brain dysfunction, the levels of SYP also serve as a functional marker of the brain (8). Therefore, in this study, we investigated the expression of SYP in the brains of rats subjected to NSC transplant following TBI.

GAP43 is a growth-associated protein that has been linked to synaptic regeneration in response to injury-associated behavioral deficits $(9,10)$. Any process that involves axonal membrane remodeling, such as neurite growth, is expected to be associated with an increased expression of GAP43 (11). We therefore assumed that an increased GAP43 mRNA and protein expression in the brains of rats subjected to NSC transplantation account for a therapeutic effect following TBI. Thus, the main objective of the present study was to investigate the effect of transplantation of NSCs on functional recovery and to determine whether transplantation of NSCs was associated with synaptic protein and regeneration-associated gene expression in a rat model of TBI.

\section{Materials and methods}

Culture of neural stem cells. Procedures were approved by the Institutional Animal Care and Use Committee of the China Medical University, Shenyang, China. Primary NSCs were isolated and cultured as previously described (12). Briefly, the forebrain tissue of embryonic 14-day (E14) Wistar rats (Experimental Animal Center of Dalian Medical University, China) was harvested under an anatomic microscope. NSCs were dissociated from cortical tissue by Accutase (Sigma, St. Louis, MO, USA), centrifuged for $5 \mathrm{~min}$ and resuspended with culture medium composed of DMEM and F12 (1:1, Sigma), $2.92 \mathrm{~g} / 100 \mathrm{ml}$ L-glutamine, $5 \mathrm{mM}$ HEPES, $7.5 \% \mathrm{NaHCO}_{3}$, $0.915 \mathrm{~g} / 100 \mathrm{ml}$ glucose, $50 \mathrm{mg} / 100 \mathrm{ml}$ heparin (all from Sigma), $1 \% \mathrm{~N}_{2}$ supplement (Gibco, Langley, OK, USA), $10 \mathrm{ng} / \mathrm{ml}$ epidermal growth factor and $10 \mathrm{ng} / \mathrm{ml} \mathrm{bFGF}$ (Invitrogen, Carlsbad, CA, USA), then seeded into $35 \mathrm{~cm}^{2}$ at $0.8 \times 10^{5}$ cells $/ \mathrm{ml}$ T-flask as suspension. Cells were maintained at $37^{\circ} \mathrm{C}$ in a humidified atmosphere with $5 \% \mathrm{CO}_{2}$. The neurospheres were transferred every 5-7 days by dissociation to a single cell suspension by Accutase and expanded for an additional 3-10 weeks in suspension.

Surgical procedures and transplantation. Sixty adult male Wister rats (Experiment Animal Laboratory of China Medical University, China) with a weight of 200-220 g were studied. The model of controlled cortical impact (CCI) brain injury was previously described $(5,13)$. Briefly, on the day of surgery, the animals were deeply anesthetized with sodium pentobarbital $(60 \mathrm{mg} / \mathrm{kg}$ intraperitoneally) and placed in a stereotactic frame (Stoelting Co., Wood Dale, IL, USA). After the skull was exposed, a 3-mm craniotomy was performed over the left parietotemporal cortex between lambda and bregma, with the dura mater left intact. CCI brain injury was induced with the use of a pneumatic impactor (tissue deformation $1 \mathrm{~mm}$, $4.5 \mathrm{~m} / \mathrm{s}$ tip velocity). CCI animals were randomly assigned to two groups for NSC transplant and saline solution control. At $72 \mathrm{~h}$ after CCI injury, neurospheres were harvested, dissociated to a single cell suspension by Accutase, counted on a hemocytometer and washed again. The cells were centrifuged at $400 \mathrm{x} \mathrm{g}$ for $5 \mathrm{~min}$ in a loose pellet, and resuspended in sterile phosphate-buffered saline (PBS). We prelabeled these cells by exposure to the non-diffusible vital fluorescent membrane dye PKH26 (Sigma) immediately before transplantation, according to the manufacturer's instructions. The cells were washed with complete medium, centrifuged and resuspended in saline solution at a density of $1 \times 10^{5}$ cells $/ \mu 1$. The non-diffusibility of PKH26 had been verified for NSCs in a previous study (14). The cells were maintained on ice during surgery. The injured animals were anesthetized again. One group received delivery of the NSCs suspension ( $3 \mu 1$ per animal, at a density of $1 \times 10^{5}$ cells $/ \mu 1$ ) to the cortex below the injury cavity in the ipsilateral hemisphere: anteroposterior, $-3.0 \mathrm{~mm}$ bregma; mediolateral, $1.0 \mathrm{~mm}$; dorsoventral, $1.1 \mathrm{~mm}(\mathrm{n}=30)$. The second group received an equivalent saline solution in the equivalent location as a control group $(\mathrm{n}=30)$. A Hamilton syringe $(10 \mu \mathrm{l})$ was slowly advanced through the dura and cortex until the desired depth was reached. Since the Stoelting quintessential injector (Stoelting Co.) was controlled, the cell suspension was injected over a period of $3 \mathrm{~min}(1 \mu \mathrm{l} / \mathrm{min})$. The needle was left in place for an additional $5 \mathrm{~min}$ and then withdrawn slowly. All animals were raised in a normal 12-h light/dark cycle.

Behavioral assessment. Gridwalk tests and latency to move were performed to evaluate the neurological motor function of rats with or without NSC transplants following TBI by blinded, trained observers. The tests were previously used almost exclusively in evaluating behavioral dysfunction in rat models of spinal injury, ischemia and other forebrain lesions, including TBI $(15,16)$. Briefly, the grid area was $64 \times 40 \times 50 \mathrm{~cm}$ (length $\mathrm{x}$ width $\mathrm{x}$ height) with $25 \times 25 \mathrm{~mm}$ diameter openings. Behavior was recorded using a camera in order to assess the animals' stepping errors. Animals were allowed 5 min to walk atop the elevated wire surface. Footfault and overall step number for each limb were counted. Thus, $\%$ footfaults was calculated using the formula (footfaults/steps+footfaults) $\times 100$, and the asymmetry difference using the formula (\% contralateral footfaults - \% ipsilateral footfaults). A step was considered to be a stepping error if it was not providing support and the foot went through the grid hole. Rats were placed on a plate and the time to move one body length $(30 \mathrm{~cm})$ was recorded. Prior to surgery, all rats were trained and reached a stable baseline level of performance within 3 days. Gridwalk tests and latency to move was measured at 1 day after injury and 1,2,4 and 8 weeks post-transplantation ( $\mathrm{n}=6$ in each group at different time points).

Histological analysis. For the in vivo studies, at 1 and 4 days and 1,2,4 and 8 weeks post-transplantation, the animals ( $\mathrm{n}=3$ in each group at different time points) were administered a lethal dose of sodium pentobarbital ( $200 \mathrm{mg} / \mathrm{kg}$ intraperitoneally) and were transcardially perfused with cold PBS and freshly hydrolyzed $4 \%$ paraformaldehyde. The brains were harvested, postfixed overnight, cryoprotected in increasing sucrose concentrations, then cryosectioned at $16 \mu \mathrm{m}$ along the coronal plane for immunohistochemistry. To evaluate the concomitance of PKH26 within neurons identified by immunoreactivity to the neuronal-specific protein of the cytoskeleton, $\beta$ III-tubulin, within astrocytes identified by immunoreactivity to glial fibrillary acidic protein (GFAP), we immunostained 3 sections 
with the highest number of transplanted cells per animal $(n=3)$, and 3 regions per section were counted for doublelabeled cells (cells positive for both PKH26 and the specific antibody). The proportion of PKH26-positive cells that were double-labeled was calculated for each animal. Sections were rinsed in $0.3 \%$ Triton X-100 in PBS (T-PBS) and preincubated in $10 \%$ normal goat serum in T-PBS. The sections were then incubated overnight at $4^{\circ} \mathrm{C}$ with one of the primary antibodies. The primary antibodies used in this study were: mouse monoclonal anti- $\beta$ III-tubulin (1:500; Santa Cruz, CA, USA), GFAP (1:200, Boster, China), mouse monoclonal anti-nestin (1:200; Santa Cruz). After being washed three times, the sections were incubated with appropriate fluorescent secondary antibody for $1 \mathrm{~h}$ at room temperature, including fluorescein isothiocyanate (FITC)-conjugated goat anti-mouse IgG (1:1000) and Texas Red AffiniPure goat anti-mouse IgG (1:1000). Fluorescent signals were detected using a Nikon compound fluorescent microscope and a Nikon C1 Plus confocal microscope (Nikon, Japan).

Western blot analysis. To evaluate the protein expression of SYP and GAP43, Western blot analysis was performed as previously described (17). The remaining animals $(n=3$ in each group at 1, 2, 4 and 8 weeks post-transplantation) were decapitated and brain tissue encompassing the transplant site was immediately obtained and dissected on a bed of ice into two parts along the centre of the injury cavity for Western blot analysis and traverse transcription-polymerase chain reaction (RT-PCR) detection (described below). Each sample was sonicated in $0.0625 \mathrm{M}$ Tris- $\mathrm{HCl}, \mathrm{pH} 6.8$, centrifuged at $12,000 \mathrm{x} \mathrm{g}$ for $15 \mathrm{~min}$ at $4^{\circ} \mathrm{C}$, and the supernatant was assayed for protein using a Bradford assay. Aliquots $(50 \mu \mathrm{g})$ of protein were boiled in denaturing sample buffer $(62.5 \mathrm{mmol} / 1$ Tris, $\mathrm{pH} 6.8,2 \%$ SDS, $5 \mathrm{mmol} / 1$ EDTA, $10 \%$ glycerol, $0.25 \%$ 2-mercaptoethanol and $0.01 \%$ bromophenol blue). Brain samples were loaded onto SDS-PAGE mini-gels, electrophoresed, and transferred to nitrocellulose membranes. After transferring, membranes were blocked with $5 \%$ milk in TBST $(0.1 \%$ Tween-20 in $20 \mathrm{mM}$ Tris- $\mathrm{HCl}, \mathrm{pH} 7.4$, and $410 \mathrm{mM} \mathrm{NaCl}$ ) for $2 \mathrm{~h}$ at room temperature. Blots were incubated overnight at $4^{\circ} \mathrm{C}$ with mouse monoclonal anti-SYP (1:1000 Sigma) and rabbit anti-GAP43 polyclonal antibody (1:500, Keygen, China). Blots were washed three times for $5 \mathrm{~min}$ each with TTBS, incubated for $1 \mathrm{~h}$ with HRP-linked secondary antibodies, washed four times for 10 min each with TTBS, and developed by the enhanced chemiluminescence Western blotting detection system kit (ECL Plus, Amersham Biosciences, NJ, USA).

Reverse transcription-polymerase chain reaction (RT-PCR) analysis. Total RNA was isolated from the tissue using a RNA isolation reagent (TRIzol, Takara, Dalian, China) according to the manufacturer's instructions and treated with RNase-free DNase (Takara). Reverse transcription (RT)-PCR was performed as previously described (18). Single-stranded cDNA synthesis was made using AMV reverse transcriptase (Takara) according to the manufacturer's protocol. PCR was performed using Taq Dynazyme (Takara) under standard conditions (5X PCR buffer, $10 \mu \mathrm{l}$; dH2O, $28.75 \mu \mathrm{l}$; Takara Ex Taq HS, $0.25 \mu \mathrm{l} ; 0.5 \mu \mathrm{l}$ of each specific primer and $10 \mu \mathrm{l}$ cDNA) using a 4 min hot-start at $94^{\circ} \mathrm{C}$ followed by 30 cycles of $94^{\circ} \mathrm{C}$ for $30 \mathrm{sec}, 55^{\circ} \mathrm{C}$ for $30 \mathrm{sec}, 72^{\circ} \mathrm{C}$ for $1 \mathrm{~min}$, followed by $10 \mathrm{~min}$ of final extension at $72^{\circ} \mathrm{C}$. Glyceraldehyde 3-phosphate dehydrogenase (GAPDH) was co-amplified as an internal control in each reaction. PCR products were analyzed by $1.5 \%$ agarose gel electrophoresis, and visualized using ethidium bromide fluorescence. The products were run on $1 \%$ agarose gel containing $10 \mathrm{ng} / \mathrm{ml}$ ethidium bromides and visualized under UV light. The primer pairs were obtained from Takara Biotechnology (Dalian Co., Ltd.), and were as follows: SYP (rat): forward, 5'-CGATGCGGGCTATGGGCAGG-3' and reverse, 5'-AGTCGCCCTGAGGCCCGTAG-3'; GAP43: forward, 5'-TGCTGTGCTGTATGAGAAGAACC-3' and reverse, 5'-GGCAACGTGGAAAGCCGTTTCTTAAAGT-3'; GAPDH: forward, 5'-TGTGATGGGTGTGAACCACGAGA-3' and reverse, 5'-GAGCCCTTCCACAATGCCAAAGTT-3'.

Quantification and statistical analysis. Transplanted cells in the CCI injury core and along the lesion border were quantified at different time points post-transplantation. Every tenth section at a thickness of $16 \mu \mathrm{m}$ throughout the thickness of the transplantation site and along the lesion border (from bregma 1.0 to $-4.0 \mathrm{~mm}$ ) was analyzed, and all $\mathrm{PKH} 26$-positive cells were counted. The number of PKH26-positive cells in all of the counted sections was multiplied by 10 to compensate for the sampling frequency (19). Differences between the mean values were analyzed using one-way ANOVA and the Student's t-test. Data are presented as the means \pm SD and the difference was considered to be significant at $\mathrm{p}<0.05$.

\section{Results}

Functional recovery of motor behavior mediated by NSC transplant. All injured groups exhibited significant motor impairment at day 1 following TBI. Measures ANOVA of forelimb and hindlimb performance in both the saline control and NSC transplant rats revealed significant time effects $(p<0.05)$. The performance of NSC transplant rats returned to pre-surgery levels at 2 and 4 weeks in forelimb and hindlimb performance, respectively. However, saline control rats had significantly more contralateral than ipsilateral footfaults relative to baseline in forelimb and hindlimb performance for 4 and 8 weeks. The Student's t-test indicated that saline control rats exhibited a significant footfault asymmetry compared to NSC transplant rats in forelimb performance in the last 4 weeks post-transplantation $(\mathrm{p}<0.05)$. Although no significant difference was found between saline control and NSC transplant rats in hindlimb performance at 1 week post-transplantation, hindlimb performance in saline control rats revealed significant difference compared to baseline and NSC transplant rats at 8 weeks (Fig. 1A and B). Latency to move was significantly longer in the saline control rats as compared to the NSC rats during 8 weeks post-transplantation $(\mathrm{p}<0.05)$. However, the performance of NSC transplant rats returned to pre-surgery levels at 2 weeks (Fig. 1C).

Survival, distribution and differentiation of engrafted rat cortical NSCs in vivo. CCI injury caused a marked cell loss in the left parietal cortex and ipsilateral hippocampus of the rats. Cells labeled PKH26 were quantified. Engrafted NSCs showed a decrease in the number of survival cells during the 8-week 
A

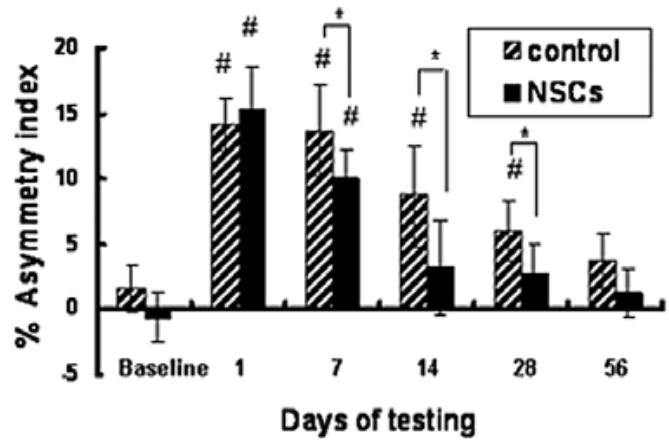

B

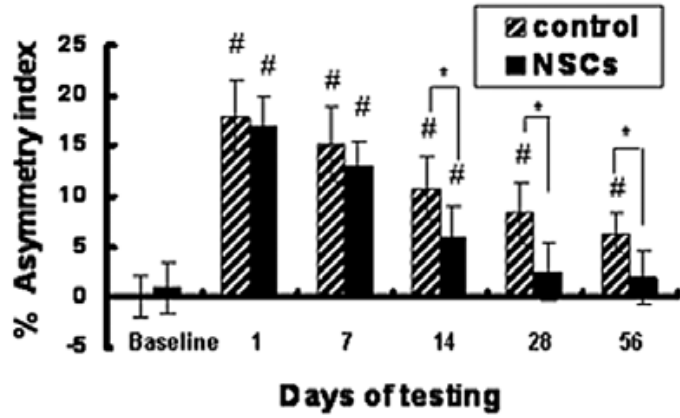

C

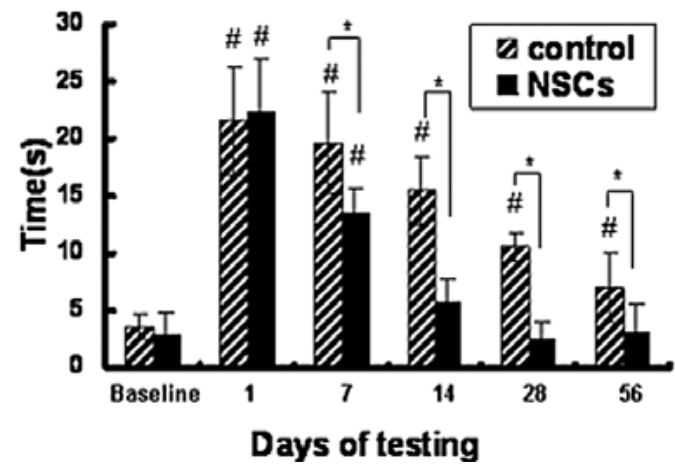

Figure 1. Behavioral functional test after TBI. (A) Forelimb and (B) hindlimb asymmetry differences (\% contralateral/ \% ipsilateral footfaults) on the gridwalk test are shown; (C) latency to move. Data are expressed as the means \pm SD ( $n=6$ in each group at different time points). ${ }^{*}<<0.05$ vs. saline control group at different time points. ${ }^{\#} \mathrm{p}<0.05$ vs. baseline.

period. The number of survival cells decreased by half at 4 days compared to the first day post-transplantation. The surviving cell was found to be $6.3 \pm 1.0$ and $4.1 \pm 0.9 \%$ of engrafted cells at 4 and 8 weeks post-transplantation, respectively (Fig. 2). The majority of the surviving cells labeled PKH26 were located within the implantation core and injection tracks within 1 week post-implantation (Fig. 2A-C). However, a number of the transplanted cells had migrated extensively outside the transplantation sites and were located in the ipsilateral cortex grandual layer in the rostral migratory stream (Fig. 2D), olfactory bulb and even the Purkinje cell layer of cerebellum at 2 weeks post-implantation. Most of these engrafted cells located in the implantation sites had undifferentiated morphology and were nestin $^{+}$at 1 week post-transplantation (data not shown); some grafted cells were $\beta$ III-tubulin ${ }^{+}$(Fig. 3A) and GFAP ${ }^{+}$ (Fig. 3B). We also found a proportion of $\beta$ III-tubulin ${ }^{+}$cells to be $4.3 \pm 1.9,8.1 \pm 2.8,13.6 \pm 2.0$ and $11.4 \pm 1.6 \%$ at $1,2,4$ and 8 weeks, respectively.

Effect of NSC transplant on the expression of synaptic protein and growth-associated protein. Western blot analysis and RT-PCR were performed to detect the protein and gene expression of SYP and GAP43 in the transplant core and boundary of CCI injury at various time points post-transplantation. Fig. 4 shows the expression of SYP and GAP43 at both the gene level (Fig. 4A-C) and protein level (Fig. 4D-F) in the NSC transplant and saline control rats at various time points post-transplantation. A significantly higher gene expression of SYP and GAP43 was found in the NSC transplant rats compared to the saline control rats during the 8 -week period post-transplantation $(\mathrm{p}<0.05)$ (Fig. $4 \mathrm{~A}-\mathrm{C})$. The expression of
SYP mRNA was increased significantly compared to saline control rats at 1 week and showed the highest level at 4 weeks post-transplantation in NSC transplant rats $(\mathrm{p}<0.01)$. GAP43 mRNA showed a continuous increase of expression in NSC transplant rats during the 8-week period post-transplantation. Measures ANOVA of gene expression GAP43 in the saline control rats revealed that there was no significant difference among the various time points post-transplantation. The protein expression of SYP and GAP43 by Western blotting confirmed these results (Fig. 4D-F).

\section{Discussion}

Our data showed that NSC transplants significantly improved neurological motor function in selected behavioral tests compared to saline control rats after experimental traumatic brain injury. The cells engrafted into the brain of rats subjected to TBI are capable of surviving and differentiating at least 8 weeks post-transplantation when transplanted into an early injured brain following TBI. We also found that the expression of synaptic protein and regeneration-associated protein in NSC transplant rats was significantly increased compared to that in saline control rats during the 8 -week period post-transplantation. These findings indicate that the transplantation of NSCs may provide a therapeutic effect partly due to the increased expression of synaptic protein and regeneration-associated protein in a rat model of TBI, and help in understanding mechanisms underlying the improvement of neurological functional of TBI treated with NSC transplant.

Previous studies showed that acute NSC transplantation may aid recovery following TBI. At 3 days post-injury, animals 

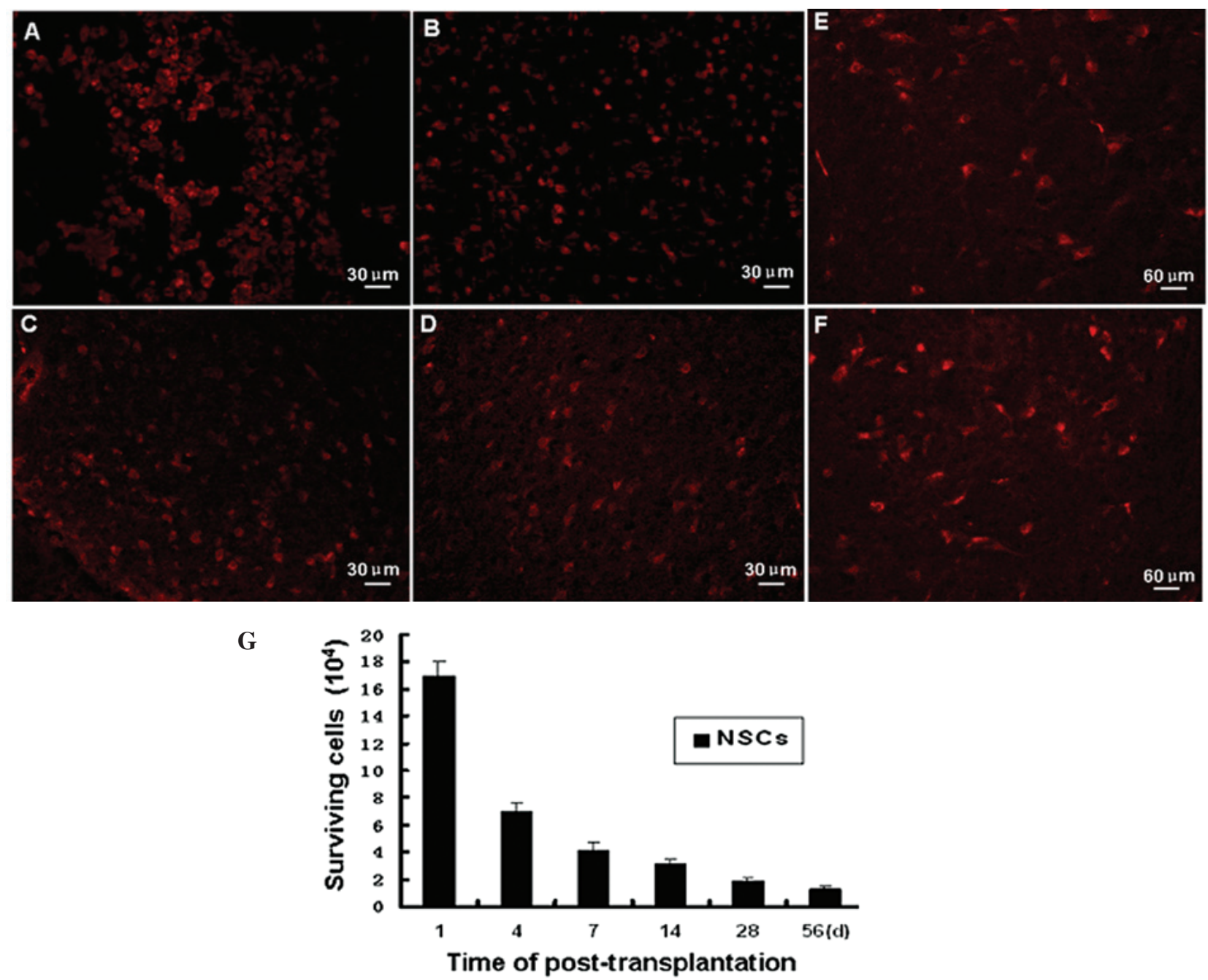

Figure 2. Survival of cortical NSCs labeled fluorescently in damaged rat brain. (A-G). The surviving cells were shown at 1,4 and 7 days and 2, 4 and 8 weeks post-transplantation following the CCI injury. (A, B and G) There was a $~ 59 \%$ reduction in the number of survival cells at 4 days compared to 1 day post-transplantation. (A-C) The engrafted cells were concentrated and round without any processes morphologically within 1 week. (D-F) Many engrafted cells extended processes and migrated into cortex grandual layer in the rostral migratory stream since 2 week post-transplantation. (G) Compared to 4 weeks, survival cells reduced slightly at 8 weeks post-transplantation. Data are expressed as the means $\pm \mathrm{SD}$ ( $\mathrm{n}=3$ in each group).

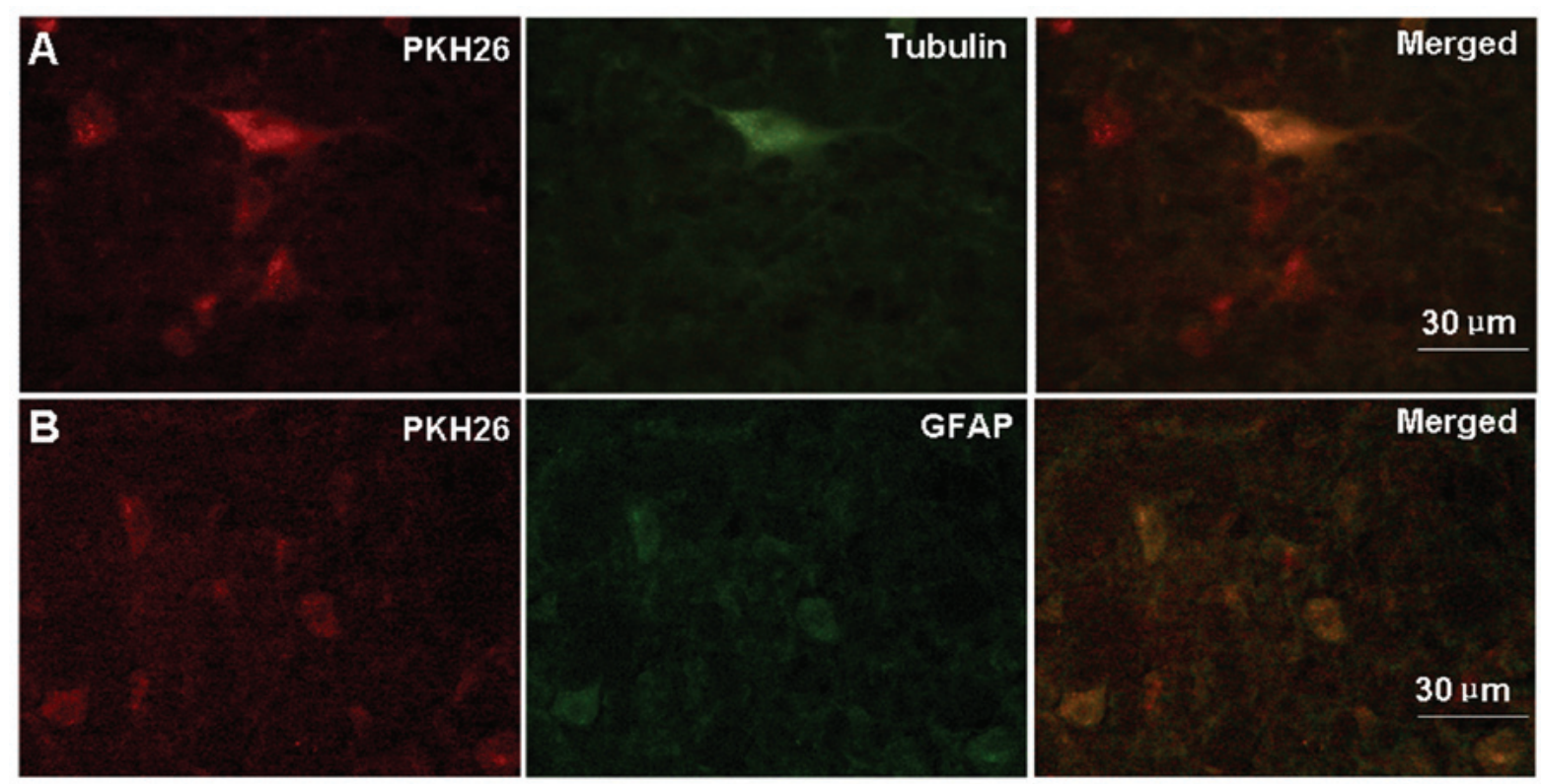

Figure 3. Differentiation of cortical NSCs labeled fluorescently in damaged rat brain. Immunostaining with neuron-specific $\beta$ III-tubulin in (A) NSC transplant rats and (B) GFAP for astrocyte shows differentiation of grafted rat cortical NSCs. 
A

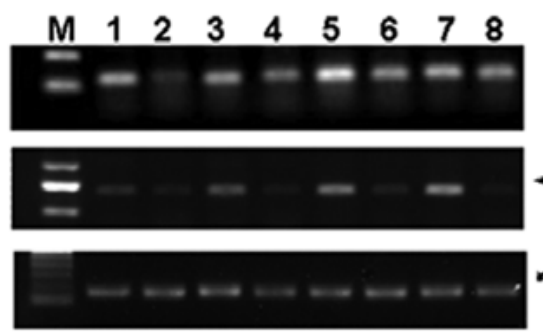

B

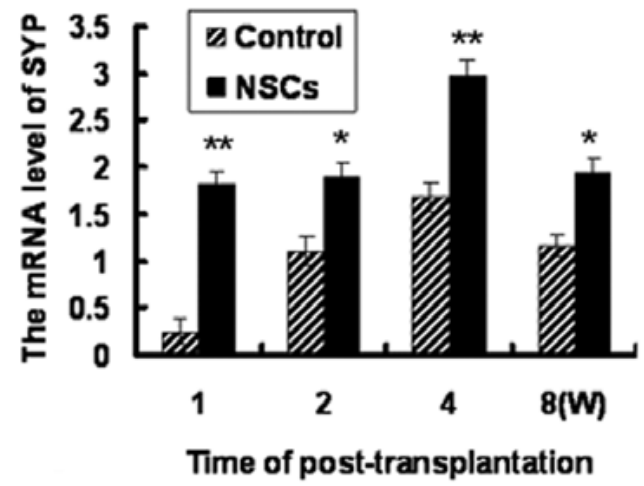

C

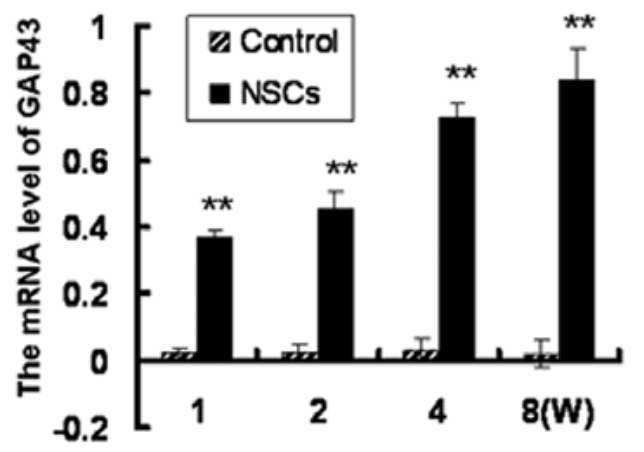

Time of post-transplantation

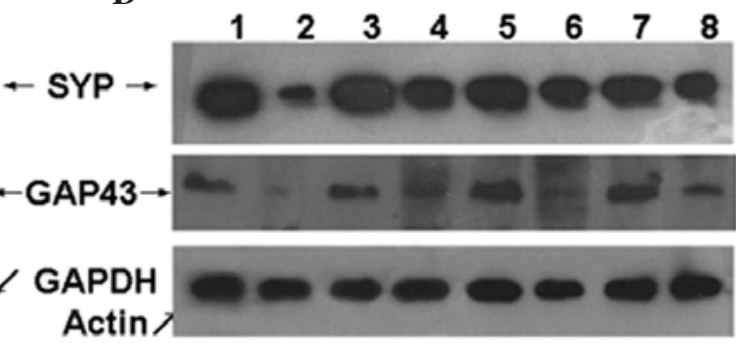

$\mathbf{E}$

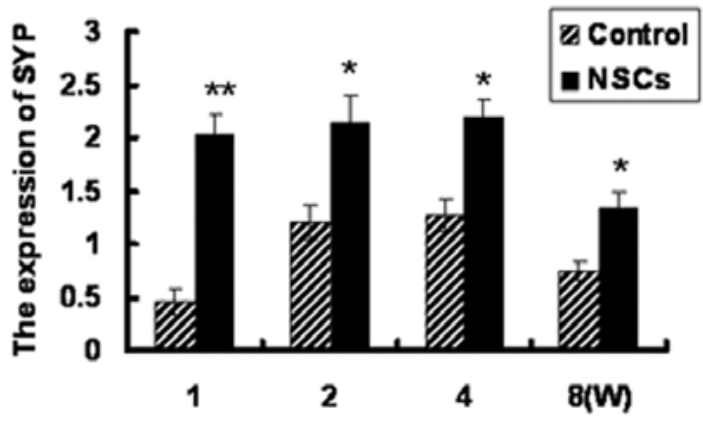

Time of post-transplantation

$\mathbf{F}$

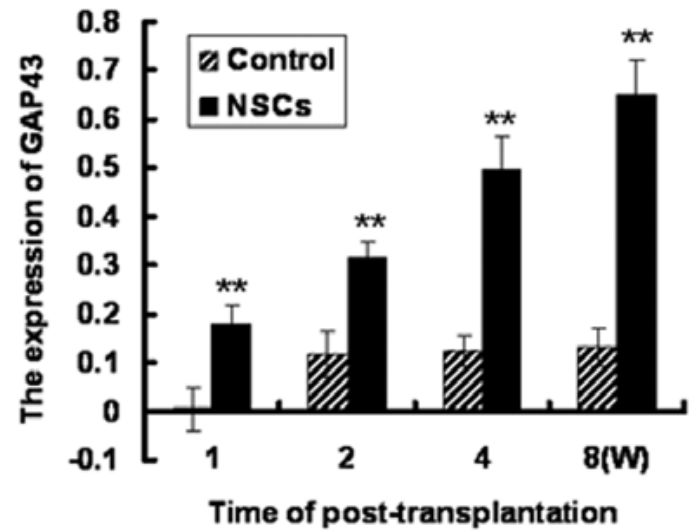

Figure 4. Expression of SYP and GAP43 in transplant site and the boundary zone of the lesion. (A and D) Lanes 1, 3, 5 and 7 from NSC transplant rats, and lanes 2, 4, 6 and 8 from the saline control rats. Lanes 1 and 2, 3 and 4,5 and 6, 7 and 8 derived from rats at 1,2, 4 and 8 weeks post-transplantation, respectively. Representative results of (A) semi-quantitative RT-PCR and (D) Western blot analysis showed a significant increase in the SYP and GAP43 gene and protein expression in NSC transplant rats compared to the saline control rats during the 8-week post-transplantation. Densitometric analysis of SYP of (B) semiquantitative RT-PCR and (E) Western blot bands. Densitometric analysis of GAP43 of (C) semi-quantitative RT-PCR and (F) Western blot bands. The intensity of each band was standardized by the band intensity of GAPDH or $\beta$-actin. Data are expressed as the means \pm SD ( $n=3$ in each group). *p $<0.05$ and ${ }^{* *}$ p $<0.01$ vs. the saline control group at different time points.

received a stereotactic injection of NSCs, and transplanted NSCs were found to survive in the traumatically injured brain, differentiate into neurons and/or glia, and attenuate motor dysfunction following TBI (5). In the current study, the model of CCI injury produced marked neurological motor dysfunction. Animals received delivery of the NSC suspension to the cortex below the injury cavity at $72 \mathrm{~h}$ after CCI injury, and the transplantation of NSCs into the injury cavity led to a significant reduction in latencies and improved the forelimb and hindlimb performance compared to saline control rats. The performance of NSC transplant rats returned to pre-surgery levels at 2 or 4 weeks in selected functional tests. However, hindlimb performance and latency to move in saline control rats revealed significant difference when comparing baseline and NSC transplant rats up to 8 weeks. These data indicated that the transplantation of NSCs promoted repair and restoration of lost function after TBI.

Our data clearly demonstrated the number of surviving cells engrafted into the rats to be $4.1 \%$ of engrafted cells at 8 weeks post-transplantation. The number of surviving cells was significantly decreased during the 8 -week period. In particular, half of the engrafted cells were lost at 4 days 
compared to 1 day post-transplantation. A significant decrease in the number of surviving cells in transplant rats at early stage post-transplantation may be associated with the post-traumatic environment, including secondary injury. A profound disruption of the blood-brain barrier and a complex of inflammatory cascades may mediate cell death and negatively affect the survival and migration of grafted NSCs $(20,21)$. TBI induced the upregulation of apoptosis-related genes during the 3-48 $\mathrm{h}$ post-injury period, which may likely be mediated by inflammation (22). This study confirms that although an acute cell transplantation strategy has shown cell survival and behavioral recovery following TBI, the acute proinflammatory microenvironment is suboptimal for the survival of grafted cells.

Previous studies indicated that transplanted NSCs ameliorated the neurological deficits and promoted repair and restoration of loss of function after TBI as early as 1 week after transplantation $(5,23)$. The mechanisms underlying the improvement in motor function have yet to be determined. It is suggested that transplanted NSCs may respond to signals present in the injured brain via cell-cell mediated repair, the release of specific neurotrasmitters, and/or the production of factors that promote neuronal growth (24-27). SYP, which is often used as a general marker protein of presynaptic nerve endings, interacts with other proteins involved in exocytosis and has a wide range of neuronal functions, including neurotransmitter release, controlled vesicle fusion, synaptogenesis, cytoskeletal structural dynamics, energy metabolism, ion homeostasis, and protein folding $(28,29)$. An in vitro study of the mRNAs encoding the presynaptic proteins SYP showed significantly increasing expression levels within the first week of differentiation and a continuous increase of expression, with the highest level at day 19 after initiation of differentiation, leading to mature synaptic contacts after 14 days of differentiation. The temporal and spatial pattern of synaptic maturation was comparable to SYP of hippocampal neurons grown in primary culture. Therefore, with respect to the general ability to create mature synaptic contacts, NSCs appear to be well-equipped to potentially compensate for lost or injured brain tissue (30). In this study, we investigated the expression of SYP in different time points post-transplantation. We found there was a significant increase of SYP in the NSC transplant rats compared to the saline control rats during the 8 weeks post-transplantation. We also found that the expression of SYP mRNA was increased significantly compared to saline control rats at 1 week and showed the highest level at 4 weeks post-transplantation in NSC transplant rats. This finding may be associated with the differentiation of NSCs beginning in the first week and reaching the highest number of neurons in engrafted NSC rats at 4 weeks post-transplantation. Differentiation of NSCs may contribute to the increase of synaptic proteins because once the development of NSCs was committed toward a neuronal phenotype, the 'program' of SYP was initiated, leading to the expression and localization of synaptic proteins at membranous attachment sites, which maturate into synapses (30).

GAP43 expression is high in the normal developing brain and decreases in adult mice, which retain the capacity to undergo synaptic remodeling (31). In this study, we observed a significant difference in the expression of GAP43 between NSC transplant rats and saline control rats following TBI. In particular, GAP43 mRNA showed a continuous increase of expression in NSC transplant rats during the 8-week period post-transplantation. It was suggested that the changes in the expression of GAP43 correlated with the branching of injured neurons (32). Therefore, an enhanced expression of GAP43 in the brain of rats subjected to NSC transplant following TBI suggests a possible reconstruction of neural circuitry and an improvement in the functional recovery following NSC transplant.

In conclusion, these results suggest that NSCs transplanted directly into the injured brain are capable of surviving, differentiating into neurons and promoting functional recovery in a rat model of TBI. Engrafted NSCs increase the expression of synaptic and growth-associated proteins in the injured brain of NSC transplant rats, which is considered to be one of the mechanisms underlying the improved functional recovery on motor behavior due to NSC transplant following TBI.

\section{Acknowledgements}

This study was supported by grants from the National Natural Science Foundation of China (No. 30850001) and the S\&T Research Project of the Education Bureau, Liaoning Province, China (No. 2008779 and 2008851). We thank Professor Xuehu Ma and Associate Professor Shui Guan from the Stem Cell and Tissue Engineering Laboratory of Dalian University of Technology for their support in culturing NSCs.

\section{References}

1. Colantonio A, Croxford R, Farooq S, Laporte A and Coyte PC: Trends in hospitalization associated with traumatic brain injury in a publicly insured population, 1992-2002. J Trauma 66: 179-183, 2009.

2. Aebischer P, Goddard M, Signore AP and Timpson RL: Functional recovery in hemiparkinsonian primates transplanted with polymer-encapsulated PC12 cells. Exp Neurol 126: 151-158, 1994.

3. Gage FH: Mammalian neural stem cells. Science 287: 1433-1438, 2000.

4. Fricker-Gates RA, Lundberg C and Dunnett SB: Neural transplantation: restoring complex circuitry in the striatum. Restor Neurol Neurosci 19: 119-138, 2001.

5. Riess P,Zhang C, Saatman KE, Laurer HL,LonghiLG, Raghupathi R, Lenzlinger PM, Lifshitz J, Boockvar J, Neugebauer E, Snyder EY and McIntosh TK: Transplanted neural stem cells survive, differentiate, and improve neurological motor function after experimental traumatic brain injury. Neurosurgery 51: 1043-1054, 2002

6. Buffo A, Carulli D, Rossi F and Strata P: Extrinsic regulation of injury/growth-related gene expression in the inferior olive of the adult rat. Eur J Neurosci 18: 2146-2158, 2003.

7. Tarsa L and Goda Y: Synaptophysin regulates activity-dependent synapse formation in cultured hippocampal neurons. Proc Natl Acad Sci USA 99: 1012-1016, 2002.

8. Shojo H and Kibayashi K: Changes in localization of synaptophysin following fluid percussion injury in the rat brain. Brain Res 1078: 198-211, 2006.

9. Benowitz LI and Routtenberg A: GAP-43: an intrinsic determinant of neuronal development and plasticity. Trends Neurosci 20: 84-91, 1997.

10. Hughes-Davis EJ, Cogen JP, Jakowec MW, Cheng HW, Grenningloh G, Meshul CK and McNeill TH: Differential regulation of the growth-associated proteins GAP-43 and superior cervical ganglion 10 in response to lesions of the cortex and substantia nigra in the adult rat. Neuroscience 135: 1231-1239, 2005.

11. Hulsebosch CE, DeWitt DS, Jenkins LW and Prough DS: Traumatic brain injury in rats results in increased expression of Gap-43 that correlates with behavioral recovery. Neurosci Lett 255: 83-86, 1998. 
12. Ma XH, Shi Y, Hou Y, Liu Y, Zhang L, Fan WX, Ge D, Liu TQ and Cui ZF. Slow-freezing cryopreservation of neural stem cell spheres with different diameters. Cryobiology 60: 184-191, 2010.

13. Smith DH, Soares HD, Pierce JS, Perlman KG, Saatman KE, Meaney DF, Dixon CE and McIntosh TK: A model of parasagittal controlled cortical impact in the mouse: cognitive and histopathologic effects. J Neurotrauma 12: 169-178, 1995.

14. Fauza DO, Jennings RW, Teng YD and Snyder EY: Neural stem cell delivery to the spinal cord in an ovine model of fetal surgery for spina bifida. Surgery 144: 367-373, 2008.

15. Baskin YK, Dietrich WD and Green EJ: Two effective behavioral tasks for evaluating sensorimotor dysfunction following traumatic brain injury in mice. J Neurosci Methods 129: 87-93, 2003.

16. Lubjuhn J, Gastens A, von Wilpert G, Bargiotas P, Herrmann O, Murikinati S, Rabie T, Marti HH, Amende I, Hampton TG and Schwaninger M: Functional testing in a mouse stroke model induced by occlusion of the distal middle cerebral artery. J Neurosci Methods 184: 95-103, 2009.

17. Bermpohl D, You Z, Korsmeyer SJ, Moskowitz MA and Whalen MJ: Traumatic brain injury in mice deficient in Bid: effects on histopathology and functional outcome. J Cereb Blood Flow Metab 26: 625-633, 2006.

18. Kong L, Zhou X, Li F, Yodoi J, McGinnis J and Cao W: Neuroprotective effect of overexpression of thioredoxin on photoreceptor degeneration in Tubby mice. Neurobiol Dis 38: 446-455, 2010

19. Mothe AJ and Tator CH: Transplanted neural stem/progenitor cells generate myelinating oligodendrocytes and Schwann cells in spinal cord demyelination and dysmyelination. Exp Neurol 213: 176-190, 2008

20. Lenzlinger PM, Morganti-Kossmann MC, Laurer HL and McIntosh TK: The duality of the inflammatory response to traumatic brain injury. Mol Neurobiol 24: 169-181, 2001.

21. Modo M, Stroemer RP, Tang E, Patel S and Hodges H: Effects of implantation site of stem cell grafts on behavioral recovery from stroke damage. Stroke 33: 2270-2278, 2002.

22. Shojo H, Kaneko Y, Mabuchi T, Kibayashi K, Adachi N and Borlongan CV: Genetic and histologic evidence implicates role of inflammation in traumatic brain injury-induced apoptosis in the rat cerebral cortex following moderate fluid percussion injury. Neuroscience 171: 1273-1282, 2010.
23. Shear DA, Tate MC, Archer DR, Hoffman SW, Hulce VD, Laplaca MC and Stein DG: Neural progenitor cell transplants promote long-term functional recovery after traumatic brain injury. Brain Res 1026: 11-22, 2004.

24. Harting MT, Sloan LE, Jimenez F, Baumgartner J and Cox CS Jr: Subacute neural stem cell therapy for traumatic brain injury. J Surg Res 153: 188-194, 2009.

25. Benninger Y, Marino S, Hardegger R, Weissmann C, Aguzzi A and Brandner S: Differentiation and histological analysis of embryonic stem cell-derived neural transplants in mice. Brain Pathol 10: 330-341, 2000

26. Bjorklund LM, Sanchez-Pernaute R, Chung S, Andersson T, Chen IY, McNaught KS, Brownell AL, Jenkins BG, Wahlestedt C, Kim KS and Isacson O: Embryonic stem cells develop into functional dopaminergic neurons after transplantation in a Parkinson rat model. Proc Natl Acad Sci USA 99: 2344-2349, 2002.

27. Karimi-Abdolrezaee S, Eftekharpour E, Wang J, Morshead CM and Fehlings MG: Delayed transplantation of adult neural precursor cells promotes remyelination and functional neurological recovery after spinal cord injury. J Neurosci 26: 3377-3389, 2006.

28. Masliah E, Honer WG, Mallory M, Voigt M, Kushner P, Hansen L and Terry R: Topographical distribution of synapticassociated proteins in the neuritic plaques of Alzheimer's disease hippocampus. Acta Neuropathol 87: 135-142, 1994.

29. Zhai RG, Vardinon-Friedman H, Cases-Langhoff C, Becker B, Gundelfinger ED, Ziv NE and Garner CC: Assembling the presynaptic active zone: a characterization of an active one precursor vesicle. Neuron 29: 131-143, 2001.

30. Liebau S, Vaida B, Storch A and Boeckers TM: Maturation of synaptic contacts in differentiating neural stem cells. Stem Cells 25: 1720-1729, 2007.

31. Jacobs KM, Neve RL and Donoghue JP: Neocortex and hippocampus contain distinct distributions of calcium-calmodulin protein kinase II and GAP43 mRNA. J Comp Neurol 336 151-160, 1993.

32. Fournier AE, Beer J, Arregui CO, Essagian C, Aguayo AJ and McKerracher L: Brain-derived neurotrophic factor modulates GAP-43 but not $\mathrm{T}$ alpha1 expression in injured retinal ganglion cells of adult rats. J Neurosci Res 47: 561-572, 1997. 